\title{
Application Article \\ Evaluation of SAR Distribution in Six-Layer Human Head Model
}

\author{
Asma Lak ${ }^{1}$ and Homayoon Oraizi ${ }^{2}$ \\ ${ }^{1}$ Young Researchers Club, Bushehr Branch, Islamic Azad University, Bushehr, Iran \\ ${ }^{2}$ Iran University of Science and Technology, Tehran, Iran
}

Correspondence should be addressed to Asma Lak; lak.asmae@gmail.com

Received 4 May 2012; Revised 2 August 2012; Accepted 16 October 2012

Academic Editor: Aurora Andújar

Copyright (C) 2013 A. Lak and H. Oraizi. This is an open access article distributed under the Creative Commons Attribution License, which permits unrestricted use, distribution, and reproduction in any medium, provided the original work is properly cited.

\begin{abstract}
The interaction between human head model and electromagnetic field sources is studied. The head models are composed of one and six layers. The six layers are skin, fat, bone, dura (the outer membrane of brain and spinal cord), CSF (colony stimulating factor), and brain. An antenna as a source of exposure is simulated too. The E-field strength distribution in both one- and six-layer human models is shown to estimate the intensity of E-field penetration in human head. Like standard models, the antenna is situated near the head model at a distance of $5 \mathrm{~mm}$. The local and average SARs (specific absorption rates) are simulated at $900 \mathrm{MHz}$ in both human head models. The results are then compared between the two models. The HFSS software is used for all the simulations. The paper wants to show that the initial model (one layer) is not a good model, because the real human head tissue is not equivalently modeled. It seems that the values of one-layer model are not reliable, so the paper considers the better and more similar human head model and compares these two models.
\end{abstract}

\section{Introduction}

It is well known that high frequency EM fields can damage human and other biological tissues by damaging molecular structure and rising of body temperature. The biological effects of radiofrequency fields and living systems can be evaluated at various levels including the molecular, subcellular, organ, or whole body environments. According to $[1,2]$, bioeffects from radiofrequency fields are classified into three categories: that is, high-level effects (thermal), intermediatelevel effects (athermal), and low-level effects (nonthermal). Thermal effects are energy depositions higher than the natural human thermoregulatory capacity. The studies show some effects due to nonthermal and athermal sources such as: blood brain barrier, morphology, immune system, gene and chromosomal morphology, enzyme activity, and tumour promotion. More information can be seen in [3-5]. In this paper dosimetry and SAR are defined. So the human head model (one and six layers) and an antenna as an exposure source are simulated in HFSS software. For validation of results two antenna types are used, dipole and PIFA. The results for SAR and E-field strength for these two models are shown and compared. Because of some limitations the standard phantom models are made of one layer. For example, because of the gel or liquid materials, it is not easy to model all tissues. For example, the human head is a multilayer tissue, and its modelling is very hard. These phantoms are not good models for the human tissue, because the real properties of tissues are different from each other. Also, the human head does not have equivalent electrical properties. So the Sixlayer phantom model is the better model of human head to simulate.

\section{Measurements of EM Field Absorption}

In this part the dosimetry is introduced. Some parameters have been used to measure EM fields. The SAR as a quantity for EM measurement at radiofrequency spectrum is defined and finally the electrical properties of tissues, that is, conductivity and permittivity, are described.

2.1. Definition of Dosimetry. According to [7] the relationship between exposure levels and electromagnetic energy deposited in the body is called "electromagnetic dosimetry." On the other hand, the electromagnetic dosimetry describes the relationship between the induced fields in biological bodies and distribution of an electromagnetic field in free 


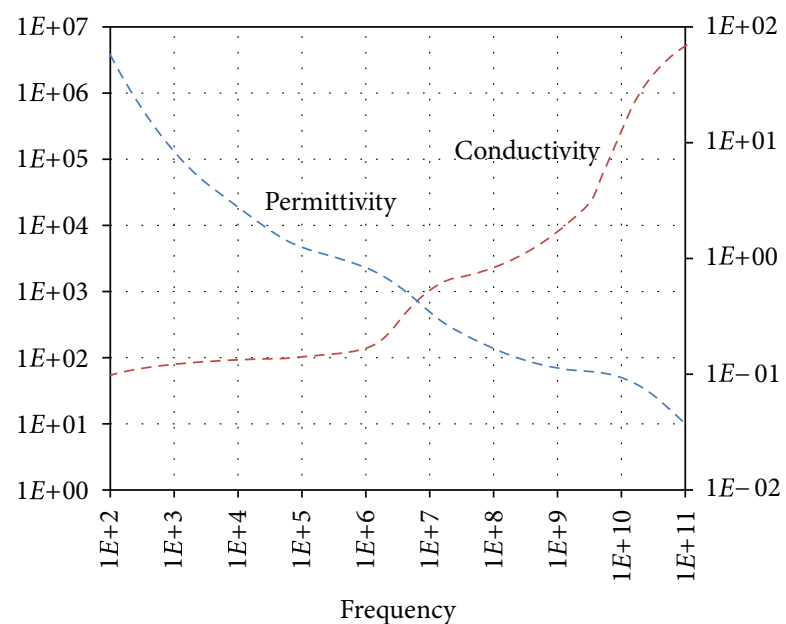

FIGURE 1: Dielectric properties spectrum of a high water content tissue [3].

space. Dosimetry information is very important to protect humans from probable electromagnetic field health hazards.

2.2. Specific Absorption Rate. By the widespread wireless device applications, such as mobile phones, the persons, and operators living and working in near electromagnetic sources, the biological effects of exposure to these electromagnetic fields are an important subject. The safety standards, such as the Federal Communication Commission (FCC), the International Commissions on Nonionizing Radiation Protection (ICNIRP), and National Radiological Protection Board (NRPB), are established for human protection and safety from electromagnetic fields. The specific absorption rate (SAR) is used to quantify the energy absorbed in tissues at radiofrequency spectrum, which is expressed in units of watts per kilogram. SAR is defined as the ratio of the absorbed power to the absorbing mass $[7,8]$. The total power absorbed in the human body is

$$
P_{\mathrm{abs}}=\int_{V} \frac{1}{2} \sigma|E|^{2} d V
$$

where $\sigma$ is the conductivity of tissue, $E$ is the electric field intensity, and $V$ is the volume of the biological tissue. SAR is defined as

$$
\operatorname{SAR}=\left(\frac{\sigma}{2 \rho}\right) E_{i}^{2}
$$

where $\sigma$ is the conductivity of tissue, $E$ is is the electric field intensity and $\rho$ is the mass density of the tissue.

2.3. Human Tissues. Human body tissues have different values of dielectric properties, that is, permittivity and conductivity [9]. These properties are functions of several variables, such as frequency, geometry and size of tissue, and water contents. For example, the dielectric constant of a high water content tissue is shown in Figure 1, as a function of frequency.

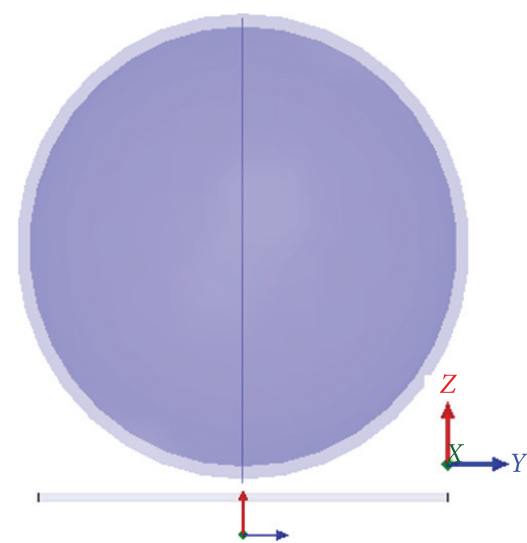

FIgURE 2: One-layer human head model defined in HFSS software.

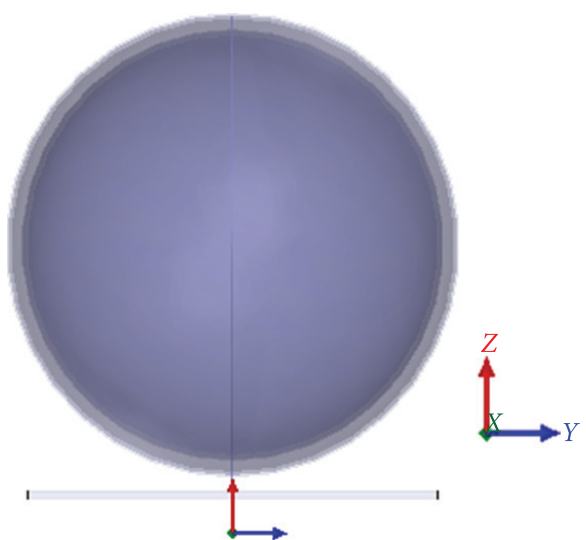

FIGURE 3: Six-layer human head model defined in HFSS software.

\section{Simulations}

Many researchers have simulated, measured, and evaluated the probable biological effects of EM fields on the human and other living systems. Several researchers have simulated the human body models, specially the human head and have evaluated the effective parameters on SAR [11-14].

3.1. Phantoms. Measurements of SAR and EM fields in the human body are not possible; consequently, the phantoms have been designed to model the human body at normal body temperatures. They have many shapes, such as spherical and human-like bodies. The liquids or gels as materials to tissues are placed in phantoms and exposure source is situated near them. One robot arm will then measure the $\mathrm{E}$ or $\mathrm{H}$ field by a probe placed at various locations near the model. A computer processor calculates the SAR. These measurement systems have several problems.

3.2. Modelling by HFSS Software. Because of the available commercial systems, the common models for SAR measurements are a thin bowl (a $5 \mathrm{~mm}$ thickness shell with 4.6 relative permittivity) containing fully the head (brain) tissue equivalent materials. Figure 2 shows this commercial model. 


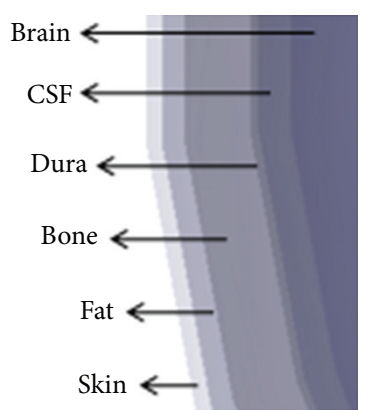

FIgURE 4: The perspective of Six-layer human head model [6].

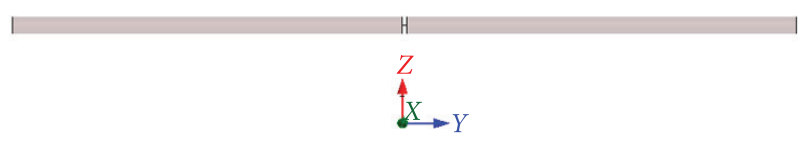

Figure 5: Dipole antenna.

TABLE 1: Specifications of one-layer head.

\begin{tabular}{lccc}
\hline Tissue & Permittivity & $\begin{array}{c}\text { Conductivity } \\
(\mathrm{S} / \mathrm{m})\end{array}$ & $\begin{array}{c}\text { Thickness } \\
(\mathrm{mm})\end{array}$ \\
\hline $\begin{array}{l}\text { Head equivalent } \\
\text { material } \\
\text { Shell }\end{array}$ & 41.5 & 0.9 & 85 \\
\hline
\end{tabular}

TABLE 2: Other specifications of model.

\begin{tabular}{lc}
\hline Dipole length & $149 \mathrm{~mm}$ \\
power & $1 \mathrm{Watt}$ \\
SAR line & $180 \mathrm{~mm}$ \\
\hline
\end{tabular}

-SAR line is a line that HFSS software measures the SAR around it.

Then a six-layer human head model has been tried instead of a one-layer common phantom model, because it models the real human head in a much better way as shown in Figure 3. This new model is composed of six spheres, similar to a sixlayer model for the human head, that is, skin, fat, bone, dura, CSF, and brain as shown in Figure 4.

Tables 1,2, and 3 show the model properties and dimensions in HFSS simulations.

3.3. Source Exposure. A dipole antenna has been used as the exposure source as shown in Figure 5. The antenna is situated at $5 \mathrm{~mm}$ distance from the head models in both one- and sixlayer models. The simulations have been done at frequency $900 \mathrm{MHz}$. The length of antenna is $149 \mathrm{~mm}$, its radius is $1.8 \mathrm{~mm}$ and the frequency of operation is $900 \mathrm{MHz}$.

3.4. Characteristics of Models. All specifications of the oneand six-layer human head model and dipole antenna are shown in Tables 1 to 3.

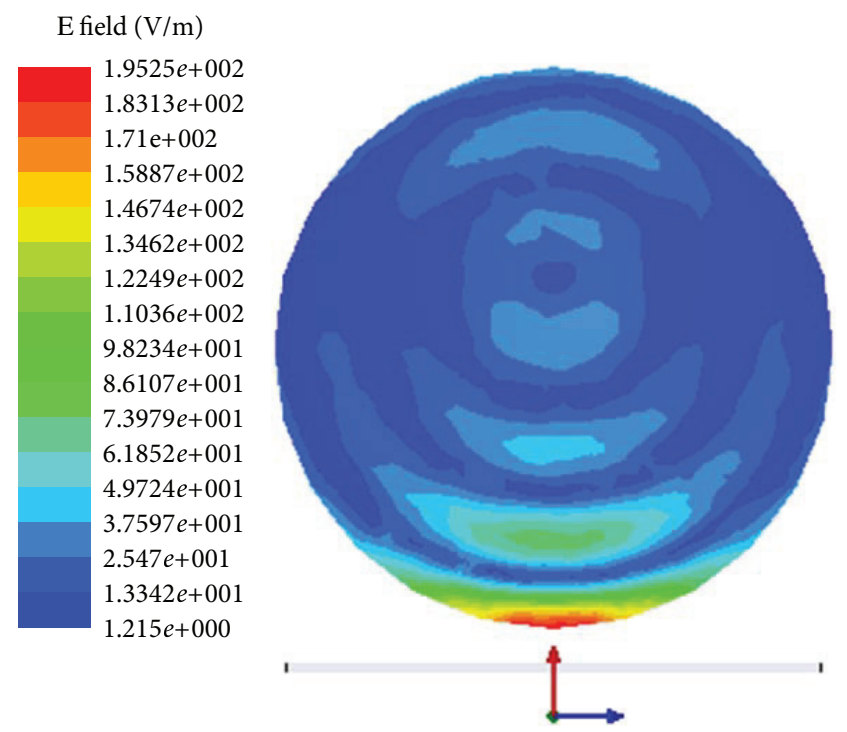

FIGURE 6: E-field strength distribution in one-layer human head model at $900 \mathrm{MHz}$.

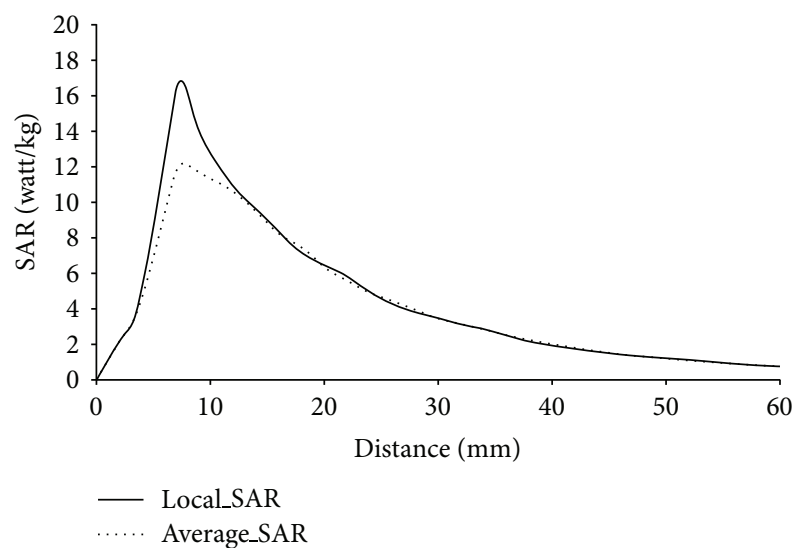

FIGURE 7: Head model as a function of the distance between the dipole and the head model.

TABLE 3: Tissue properties and thickness of six-layer human head model [6].

\begin{tabular}{lccc}
\hline Tissue & Permittivity & Conductivity $(\mathrm{S} / \mathrm{m})$ & Thickness $(\mathrm{mm})$ \\
\hline Skin & 40.7 & 0.65 & 1 \\
Fat & 10 & 0.17 & 0.14 \\
Bone & 20.9 & 0.33 & 0.41 \\
Dura & 40.7 & 0.65 & 0.5 \\
CSF & 79.1 & 2.14 & 0.2 \\
Brain & 41.1 & 0.86 & 81 \\
\hline
\end{tabular}

\section{Results}

In this section the results of human head model in one and six layer and antenna model both dipole and PIFA are shown. Also the results for SAR and electric fields strength are compared. 

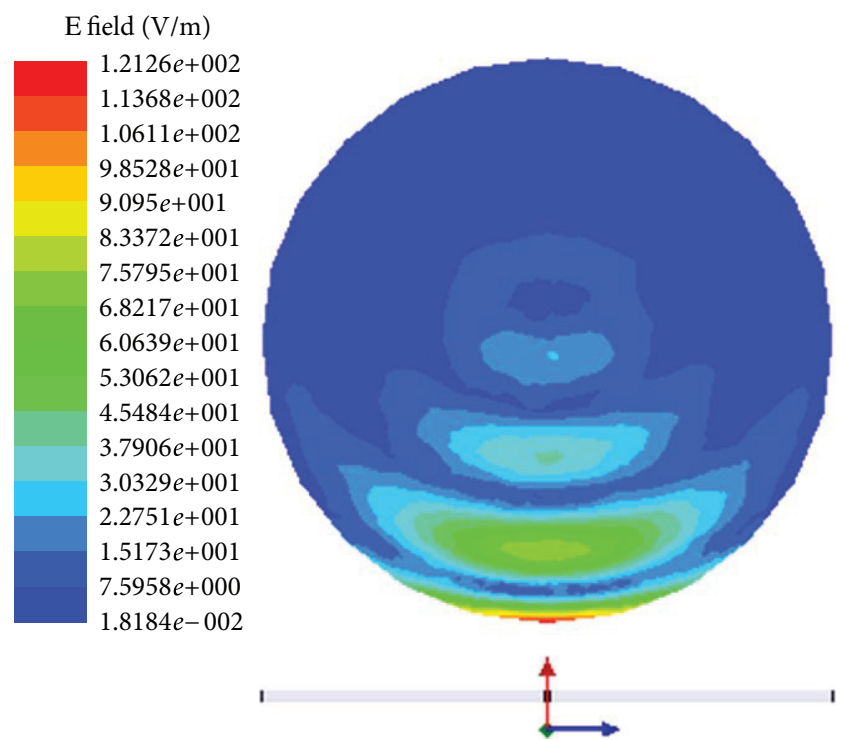

FIgURE 8: E-field strength in brain tissue at $900 \mathrm{MHz}$.
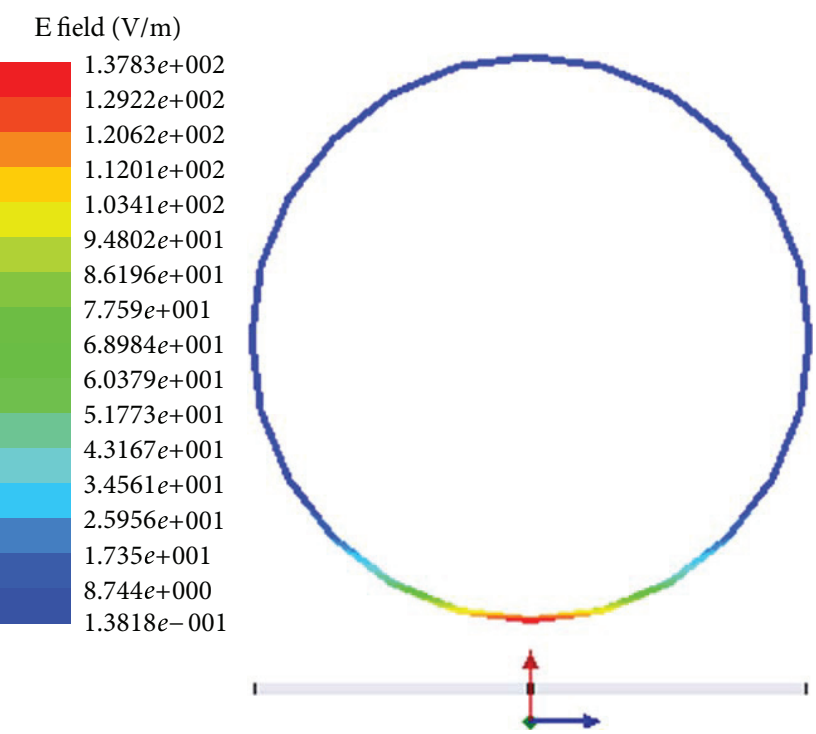

Figure 9: E-field strength in CSF tissue at $900 \mathrm{MHz}$.

TABLE 4: E-field strength in six-layer model, dipole antenna.

\begin{tabular}{lc}
\hline Tissue & E-field strength $(\mathrm{V} / \mathrm{m})$ \\
\hline Skin & $1.80 \times 10^{2}$ \\
Fat & $1.77 \times 10^{2}$ \\
Bone & $1.67 \times 10^{2}$ \\
Dura & $1.40 \times 10^{2}$ \\
Csf & $1.37 \times 10^{2}$ \\
Brain & $1.21 \times 10^{2}$ \\
\hline
\end{tabular}

4.1. "One-Layer" Human Head Model with Dipole Antenna at $0.9 \mathrm{GHz}$. This model consists of a shell with $5 \mathrm{~mm}$ thickness and a sphere with $85 \mathrm{~mm}$ radius as the head equivalent materials. According to (2), the SAR has a direct relationship to

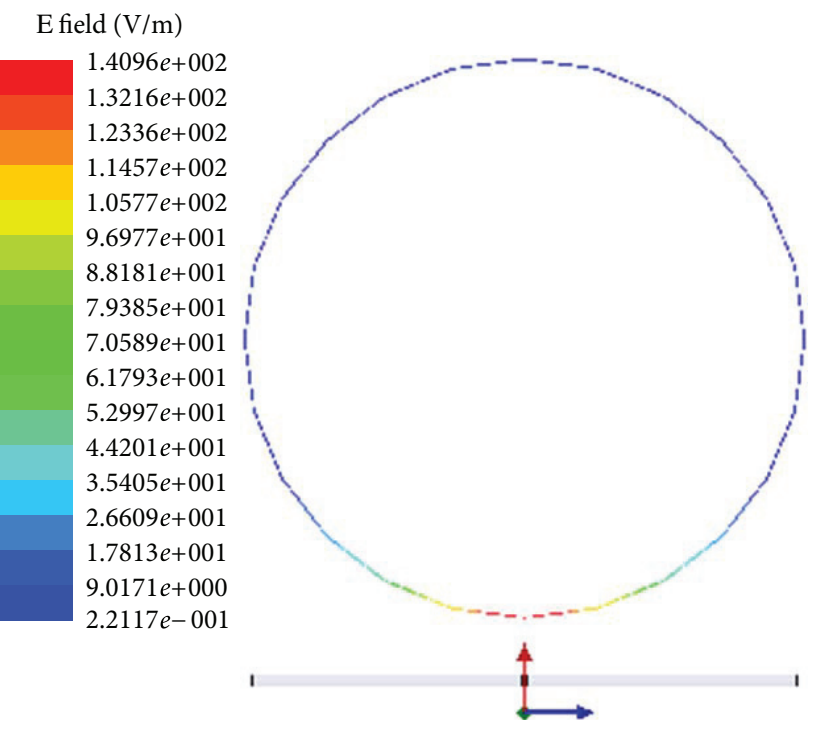

Figure 10: E-field strength in Dura tissue at $900 \mathrm{MHz}$.

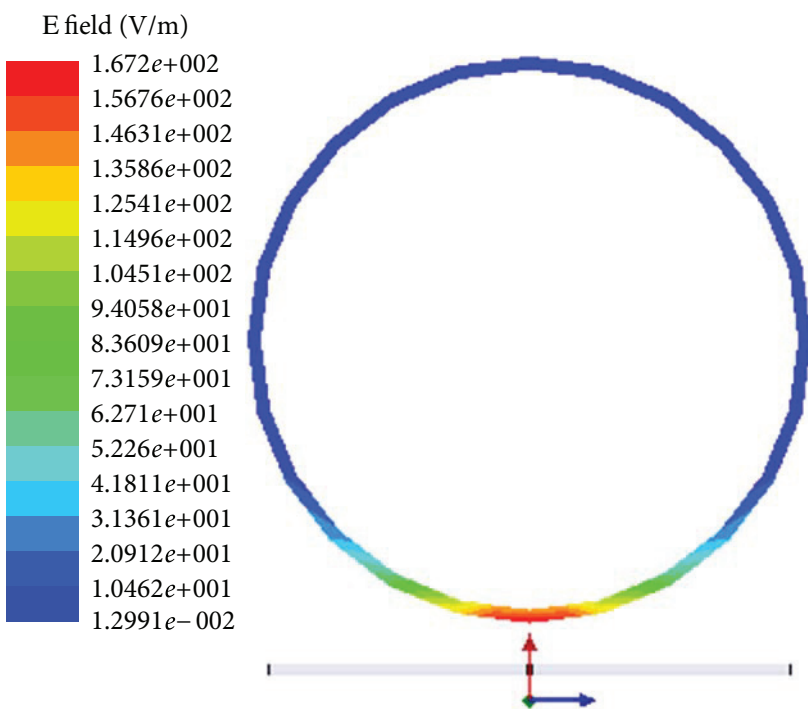

FIGURE 11: E-field strength in bone tissue at $900 \mathrm{MHz}$.

the E-field strength. Because of the importance of the electric field in SAR calculations, the E-field strength distribution in the one-layer head model is shown in Figure 6. The maximum value is at the nearest point to the source exposure (red colour). The local and average SAR as a function of the distance between the dipole and the head model is shown in Figure 7.

4.2. "Six-Layer" Human Head Model with Dipole Antenna at $0.9 \mathrm{GHz}$. The E-field distribution in the six-layer model is simulated and shown in Figures 8, 9, 10, 11, 12, and 13. The E-field strength is simulated in all the six layers, by the aforementioned procedure.

The result of simulations is shown in the Table 4. As shown the E-field strength is decreasing by the distance 
TABLE 5: Compression between SAR in two models (one- and six-layer model by Dipole antenna).

\begin{tabular}{|c|c|c|c|c|}
\hline Max SAR (Watt/Kg) & Layer & Conductivity & Local SAR & Average SAR \\
\hline \multirow{2}{*}{ One layer + dipole } & Shell & 0 & 0 & 0 \\
\hline & Head equivalent material & 0.9 & $1.8 \times 10^{+1}$ & $1.2 \times 10^{+1}$ \\
\hline \multirow{6}{*}{ Six layers + dipole } & Skin & 0.65 & $1.39 \times 10^{+2}$ & $2.2 \times 10^{+1}$ \\
\hline & Fat & 0.17 & 3. $57 \times 10^{+1}$ & 7.77 \\
\hline & Bone & 0.33 & $5.06 \times 10^{+1}$ & $2.05 \times 10^{+1}$ \\
\hline & Dura & 0.65 & $6.6 \times 10^{+1}$ & 7.83 \\
\hline & CSF & 2.14 & $2.16 \times 10^{+2}$ & $7.75 \times 10^{+1}$ \\
\hline & Brain & 0.86 & $8.8 \times 10^{+1}$ & $4.5 \times 10^{+1}$ \\
\hline
\end{tabular}

TABLE 6: E-field strength in six layers (PIFA antenna).

\begin{tabular}{lc}
\hline Tissue & E-field strength $(\mathrm{V} / \mathrm{m})$ \\
\hline Skin & $7.99 \times 10^{-1}$ \\
Fat & $7.8 \times 10^{-1}$ \\
Bone & $7.4 \times 10^{-1}$ \\
Dura & $6.4 \times 10^{-1}$ \\
CSF & $6.2 \times 10^{-1}$ \\
Brain & $5.2 \times 10^{-1}$ \\
\hline
\end{tabular}

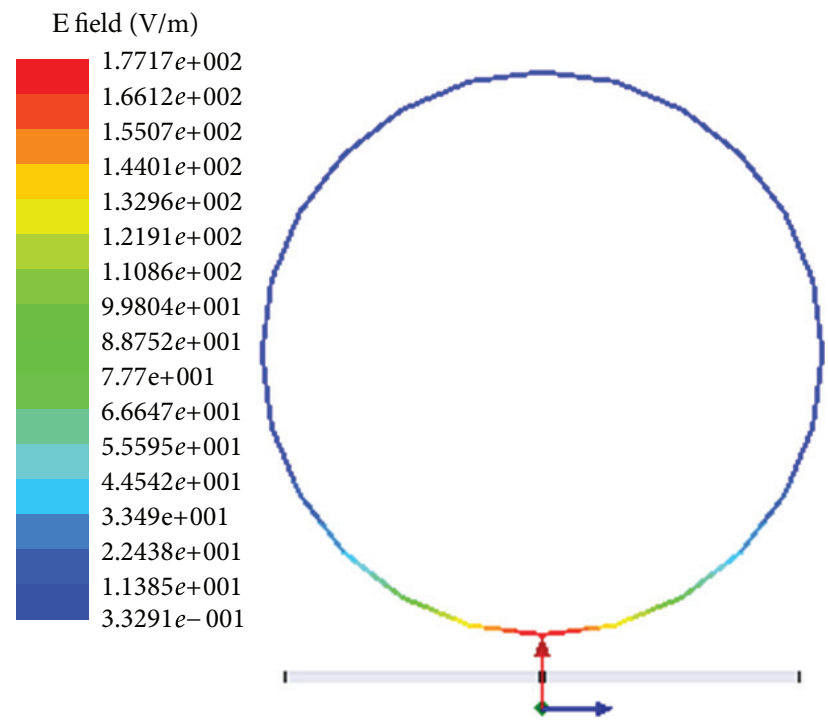

FIgURE 12: E-field strength in fat tissue at $900 \mathrm{MHz}$.

from the source, consequently the maximum value of E-field strength in the brain tissue as an internal layer is the lowest.

The comparison of SAR between one- and six-layer head models are given in Table 5.

The values show that the maximum of SAR strength in the six layers is more than one layer. It says that the standard model (that is used in standard systems) may be not suitable and complete and does not show the accurate model of human tissues.

4.3. "Six-Layer" Human Head Model with PIFA Antenna at $0.9 \mathrm{GHz}$. For further consideration of the problem, simulation is repeated for head model, but with PIFA antenna at

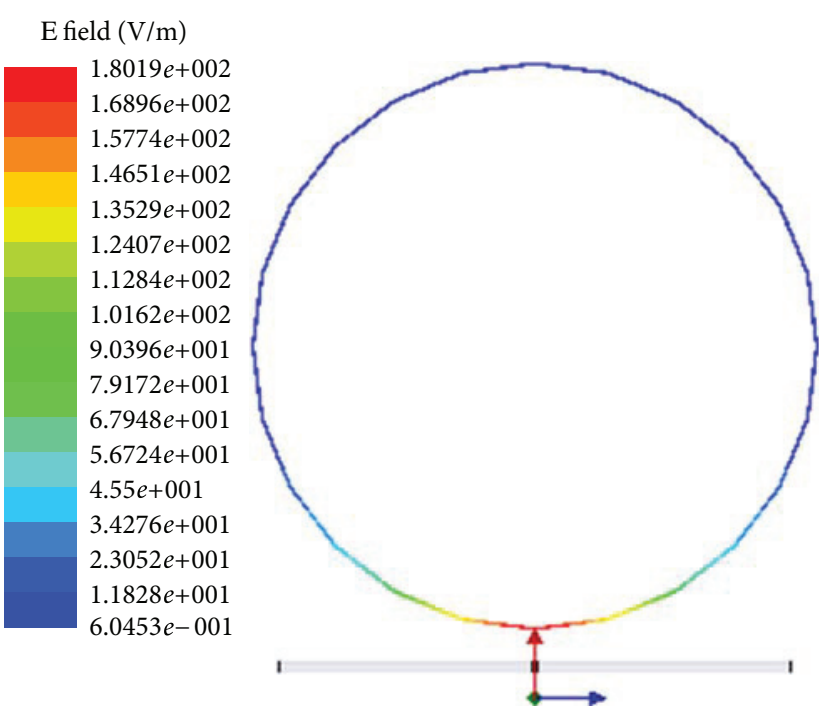

FIGURE 13: E-field strength in skin tissue at $900 \mathrm{MHz}$.

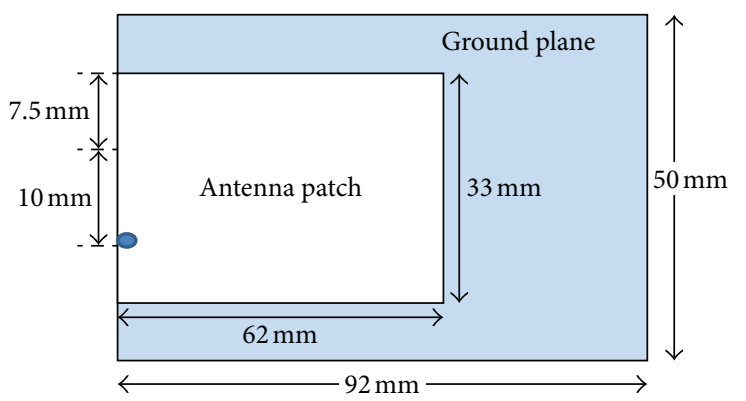

Figure 14: The structure of PIFA antenna at $0.9 \mathrm{GHz}$ [10]. * Height of the antenna patch from the ground plane is the $7.5 \mathrm{~mm}$.

$900 \mathrm{MHz}$ [10]. The geometry of antenna is shown in Figures 14,15 , and 16. The other specifications of the model are according to Table 1 . The results for the E-field strength and SAR simulations are shown in Figures 17, 18, 19, 20, 21, and 22.

The results show that the E-field strength is decreasing by increasing the distance from the source: consequently, the maximum value of E-field strength in the brain tissue at the internal layer is the lowest. The results for PIFA antenna are similar to those of dipole antenna, with regards 
TABLE 7: Compression between SAR in two models (one- and six-layer model by PIFA antenna).

\begin{tabular}{lcccc}
\hline Max SAR (watt/Kg) & Layer & Conductivity & Local SAR & Average SAR \\
\hline \multirow{2}{*}{ One layer + PIFA } & Shell & 0 & 0 & 0 \\
& Head equivalent material & 0.9 & $1.27 \times 10^{-4}$ & $2.4 \times 10^{-3}$ \\
& Skin & 0.65 & $1.4 \times 10^{-3}$ & $0.83 \times 10^{-4}$ \\
\hline & Fat & 0.17 & $1.27 \times 10^{-3}$ \\
Six layers + PIFA & Bone & 0.33 & $1 \times 10^{-3}$ & $0.9 \times 10^{-3}$ \\
& Dura & 0.65 & $5 \times 10^{-3}$ & $0.99 \times 10^{-3}$ \\
& CSF & 2.14 & $2 \times 10^{-3}$ & $3.52 \times 10^{-3}$ \\
& Brain & 0.86 & $2 \times 10^{-3}$ & $1.47 \times 10^{-3}$ \\
\hline
\end{tabular}

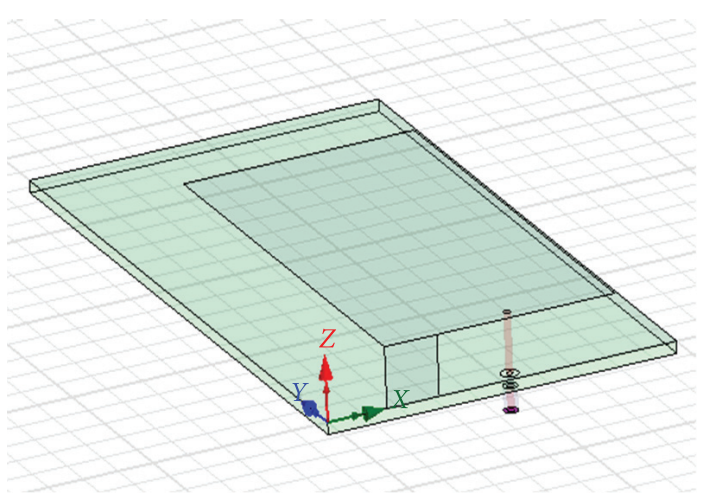

FIGURE 15: PIFA antenna at $900 \mathrm{MHz}$.

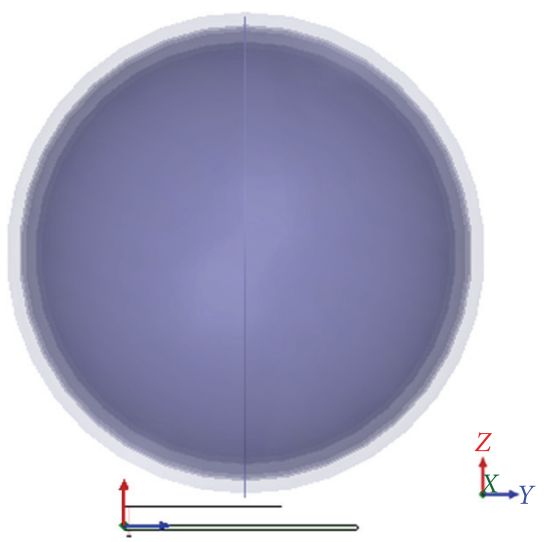

FIgURE 16: Six-layer human head model with PIFA antenna.

to the decreasing values of SAR with increasing the distance between the source and head. Table 6 shows the results for PIFA antenna.

Table 7 shows the SAR maximum strength values in oneand six-layer model by PIFA antenna as a source exposure. According to these results it has been seen that the SAR values in these simulation depend on the distance from antenna and conductivity value of tissues. For example in one-layer model shell is the nearer layer to the exposure source, so although it has lower conductivity, the SAR is more than head equivalent material. Also in six-layer model the SAR is varied by conductivity and distance from the exposure source too.
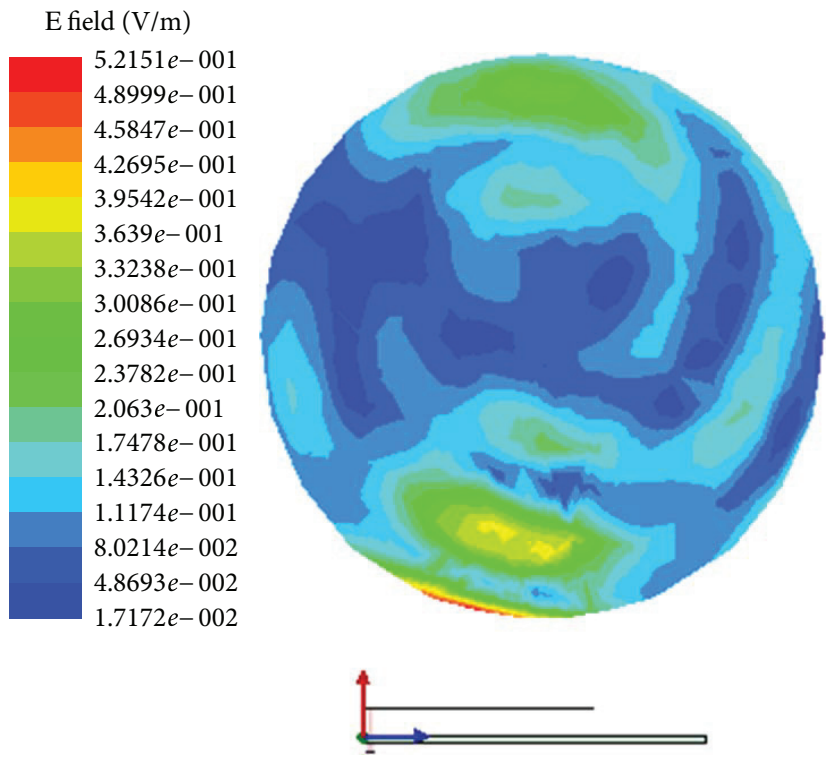

FIGURE 17: E-field strength in brain tissue at $900 \mathrm{MHz}$.

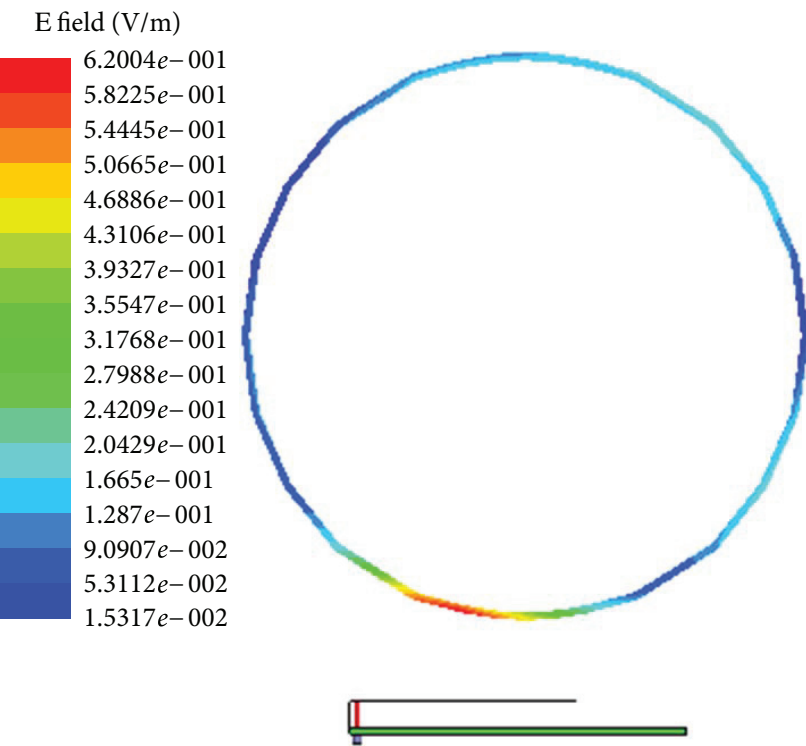

FIGURE 18: E-field strength in CSF tissue at $900 \mathrm{MHz}$. 

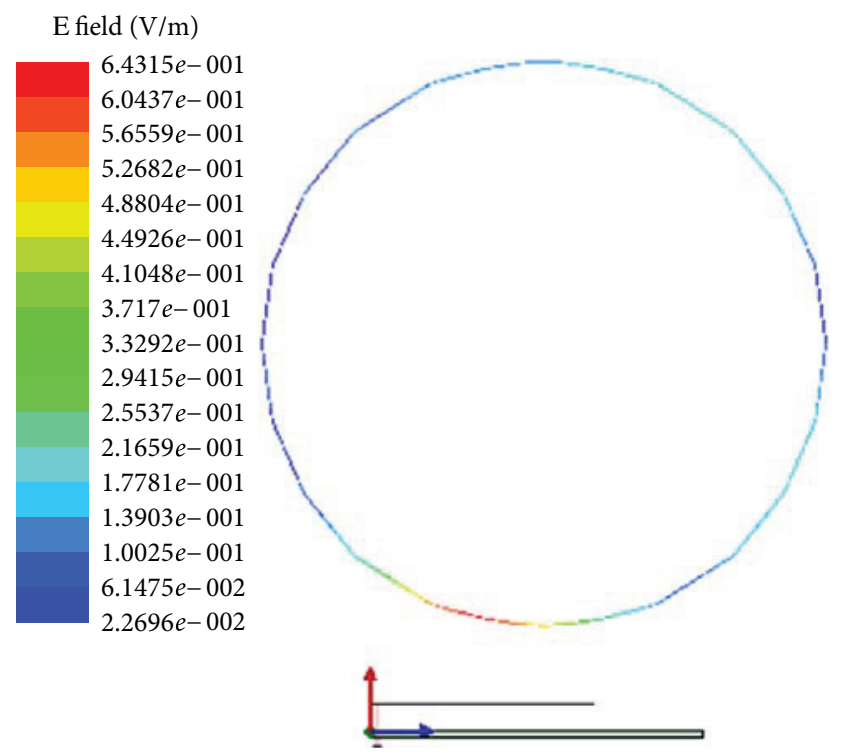

Figure 19: E-field strength in Dura tissue at $900 \mathrm{MHz}$.
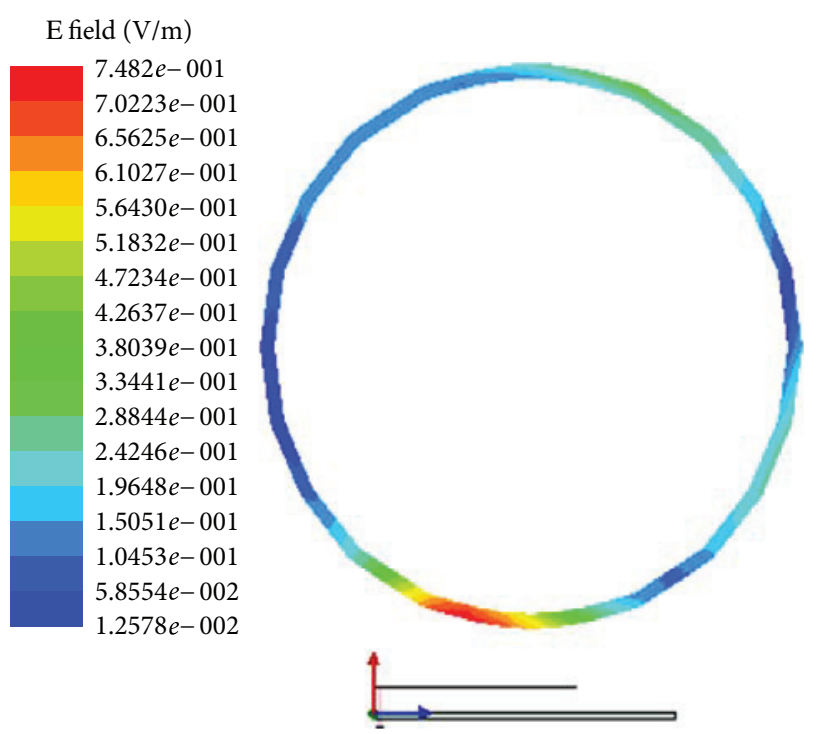

Figure 20: E-field strength in bone tissue at $900 \mathrm{MHz}$.

For example, dura and skin have same conductivity but the skin is the nearer layer to antenna, so it has more SAR.

The penetration of fields on human body, for example, human head, has been considered by many researchers. Some of these researches are in simulation by software and some of them are done by measurement systems (human phantom models). For more information the references [15-18] can be seen. So, at the same frequency of exposure source, the results may be different because of the difference in human body model.

\section{Conclusions}

The simulations are done at $900 \mathrm{MHz}$, because it is the standard for the mobile communication systems. The resulting

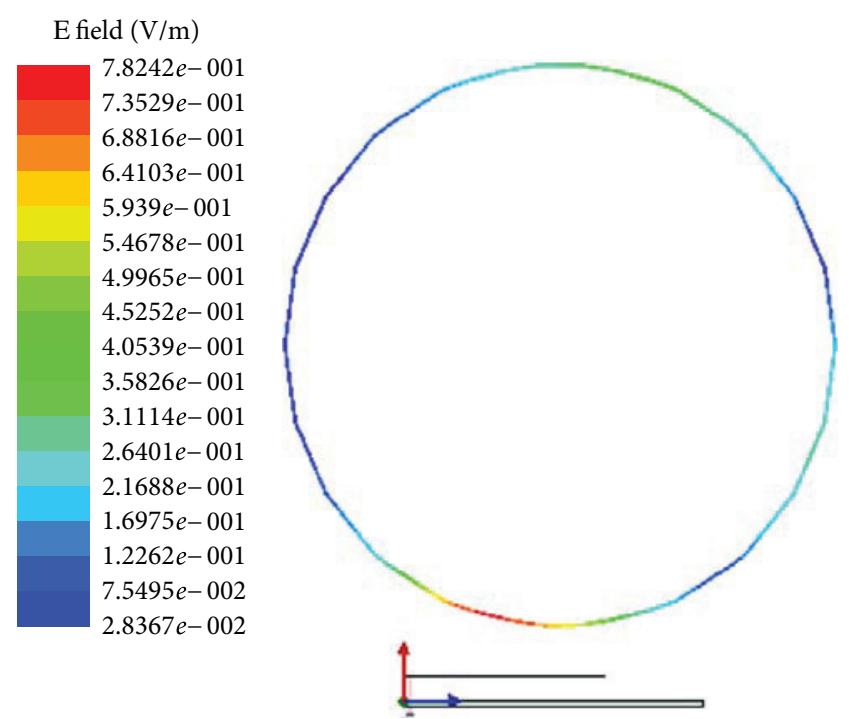

Figure 21: E-field strength in fat tissue at $900 \mathrm{MHz}$.
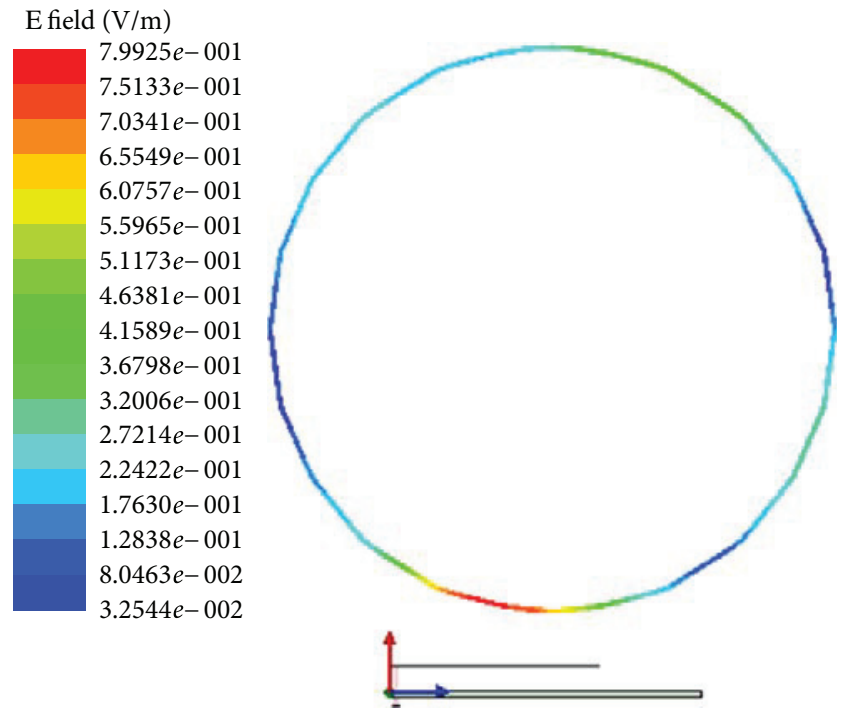

FIgUre 22: E-field strength in skin tissue at $900 \mathrm{MHz}$.

data show that when the human body tissue especially the human head (because of placing the cell phone near the head) is exposed to EM fields; the fields penetrate in all the human head tissues. The E-field strength penetration and SAR deposition depend on tissue material properties (conductivity, permittivity, and permeability). By increasing the conductivity, SAR increases too. In this paper two human head models have been used, one and six layer. The onelayer human head model is simple and easy to use for simulation and measurement system, because the human body equivalent materials are gel or liquid in commercial SAR measurement system. But it has no assurance and the measurements are not reliable, because it does not show a good and real model of human head.So Six-layer head model has been used. In Tables 5 and 7, the local and average SAR for one and six layer is shown. The compression of both local 
and average SAR in six-layer models is more than one layer. Furthermore, the commercial models (viz., one layer model) may not be good models for the human body, because the results show that the EM field penetration is higher in a sixlayer model. So the design of a better model is unavoidable for the study of the exposure of human body to EM field sources. The result for another mobile antenna, that is, PIFA is repeated and showes similar results. Results show that by PIFA antenna the E-field strengths are very lower. According to (2) the SAR is lower too.

\section{References}

[1] M. H. Repacholi, "Low-level exposure to radiofrequency electromagnetic fields: health effects and research needs," Bioelectromagnetics, vol. 19, no. 1, pp. 20-32, 1998.

[2] A. G. Pakhomov, Y. Akyel, O. N. Pakhomova, B. E. Stuck, and M. R. Murphy, "Current state and implications of research on biological effects of millimeter waves: a review of the literature," Bioelectromagnetics, vol. 19, no. 7, pp. 393-413, 1998.

[3] F. S. Barnes and B. Greenebaumby, Bioengineering and Biophysical Aspects of Electromagnetic Fields, Handbook of Biological Effect of Electromagnetic Fields, Taylor \& Francis Group, London, UK, 3rd edition, 2007.

[4] P. Vecchia, R. Matthes, G. Ziegelberger, James Lin, and R. Saunders, Exposure To High Frequency Electromagnetic Fields, Biological Effects and Health Consequences (100 KHz-300 GHz), International Commission on Non-Ionizing Radiation Protection, Oberschleissheim, Germany, 2009.

[5] J. C. Lin, "Effects of microwave and mobile telephone exposure on memory process," IEEE Antenna and Propagation Magazine, vol. 42, no. 3, pp. 118-120, 2000.

[6] H. Khodabakhshi and A. Cheldavi, "Irradiation of a six-layered spherical model of human head in the near field of a half-wave dipole antenna," IEEE Transactions on Microwave Theory and Techniques, vol. 58, no. 3, pp. 680-690, 2010.

[7] D. A. Sánchez-Hernández, High Frequency Electromagnetic Dosimetry, 2009.

[8] J. C. Lin, Advances in Electromagnetic Fields in Living Systems, vol. 4, Springer, New York, NY, USA, 2005.

[9] C. Gabriel, "The dielectric properties of tissues," in Radiofrequency Radiation Dosimetry and Its Relationship To the Biological Effects of Electromagnetic Fields, B. J. Klauengerg and D. Miklavic, Eds., vol. 82 of Nato Science Series, pp. 75-84, High Technology, London, UK, 2000.

[10] C. W. Khoo, Multi-band antenna for handheld transceivers [Ph.D. thesis], 2002.

[11] A. Lak, H. Oraizi, and F. Mohsenifard, "Risk from electromagnetic fields," in Proceedings of the 3rd International Conference on Mechanical and Electrical Technology (ICMET '11), Dalian, China, August 2011.

[12] L. Asmae and O. Homayoon, "Simulation and evaluation of specific absorption rate in human body in high frequency electromagnetic fields," in Advanced Materials Research, vol. 433-440, pp. 5489-5493, Trans Tech Publications, Zurich, Switzerland, 2012.

[13] M. R. I. Faruque, M. T. Islam, and N. Misran, "Analysis of SAR levels in human head tissues for four types of antennas with portable telephones," Australian Journal of Basic and Applied Sciences, vol. 5, no. 3, pp. 96-107, 2011.
[14] "International Standard IEC 62209-1, human exposure to radio frequency fields from hand-held and body-mounted wireless communication devices-human models, instrumentation, and procedures-Part 1: procedure to determine the specific absorption rate (SAR) for hand-held devices used in close proximity to the ear (frequency range of $300 \mathrm{MHz}$ to $3 \mathrm{GHz}$ )," IEC publication, 2005.

[15] A. Andújar, J. Anguera, C. Picher, and C. Puente, "Human head interaction over ground plane booster antenna technology: functional and biological analysis," Progress in Electromagnetics Research, vol. 41, pp. 153-185, 2012.

[16] A. Cabedo, J. Anguera, C. Picher, M. Ribó, and C. Puente, "Multiband handset antenna combining a PIFA, slots, and ground plane modes," IEEE Transactions on Antennas and Propagation, vol. 57, no. 9, pp. 2526-2533, 2009.

[17] S. Risco, J. Anguera, A. Andújar, C. Picher, and J. Pajares, "Comparison of a monopole and a PIFA handset antenna in the presence of the human head," Microwave and Optical Technology Letters, vol. 54, no. 2, pp. 454-459, 2012.

[18] A. Lak and H. Oraizi, "The effect of distance of human head model from EM sources on SAR," Journal of Basic and Applied Scientific Research, vol. 2, no. 9, pp. 9446-9453, 2012. 

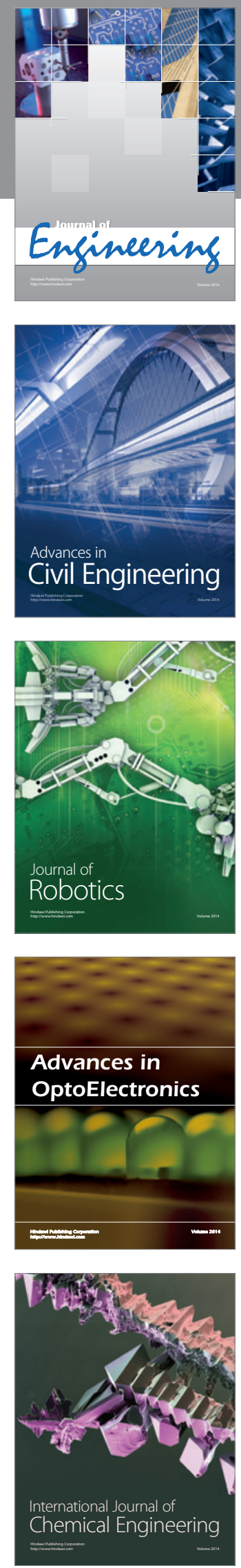

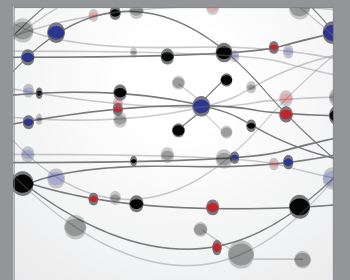

The Scientific World Journal
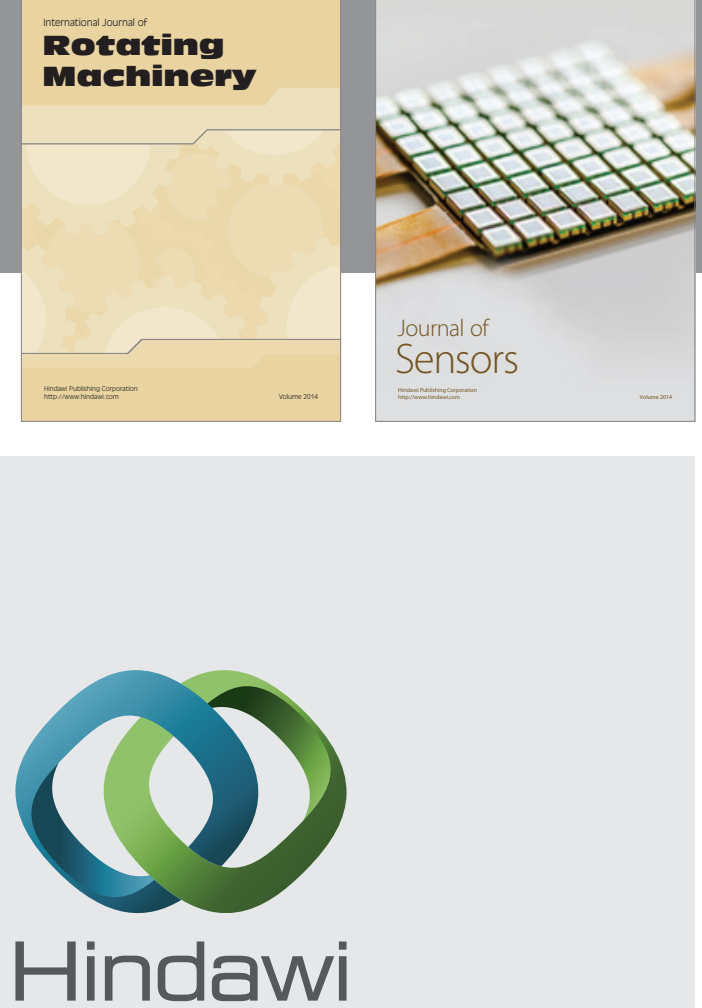

Submit your manuscripts at http://www.hindawi.com
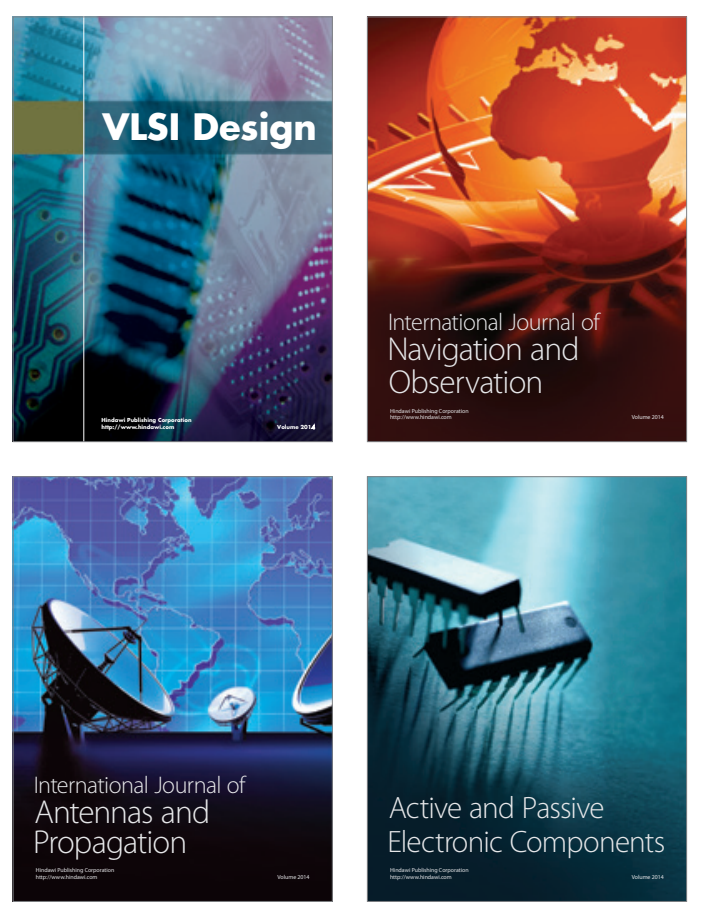
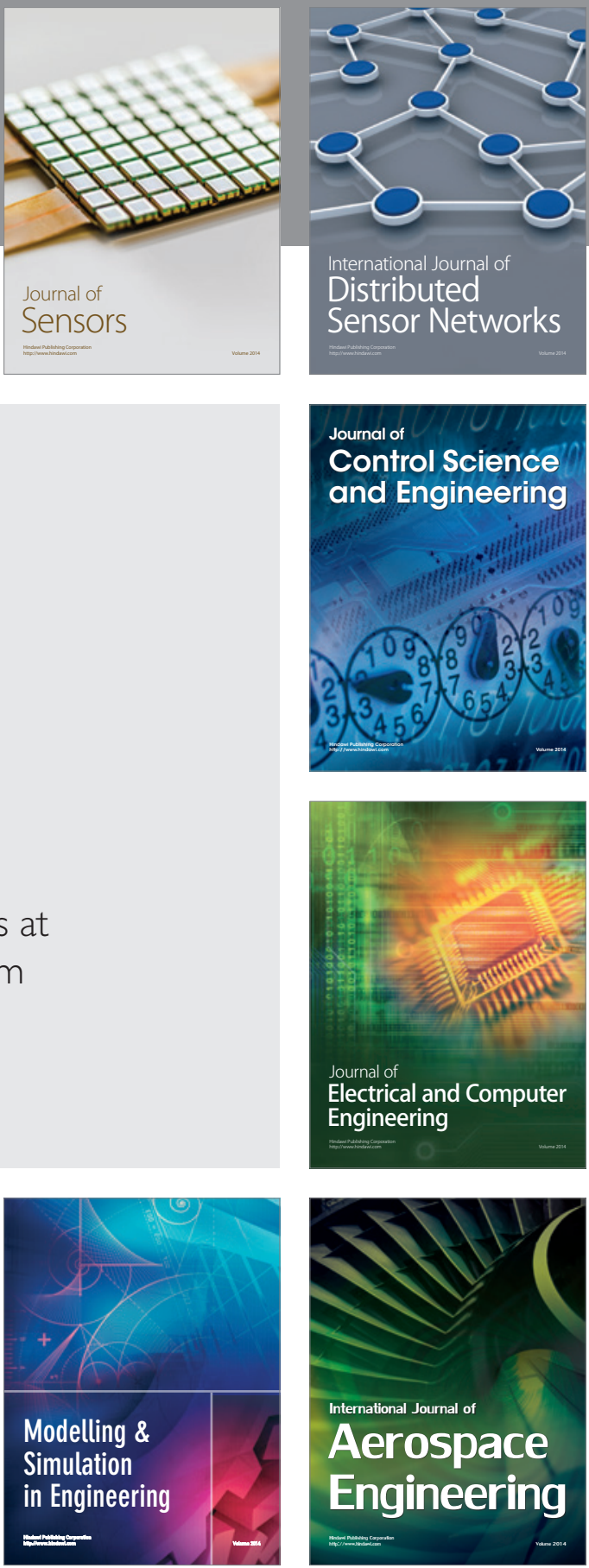

Journal of

Control Science

and Engineering
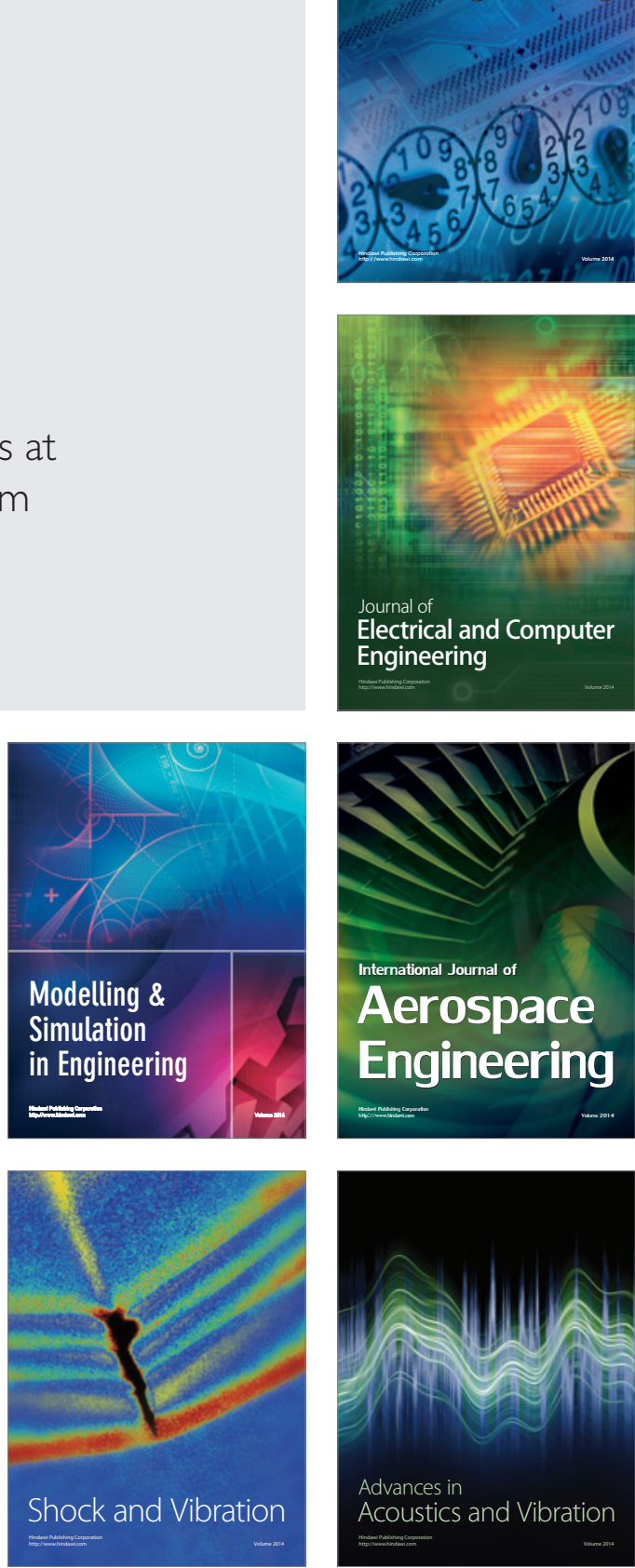